\title{
Neural organization of the defensive behavior system responsible for fear
}

\author{
MICHAEL S. FANSELOW \\ University of Califormia, Los Angeles, Califormia
}

\begin{abstract}
This paper applies the behavior systems approach to fear and defensive behavior, examining the neural circuitry controlling fear and defensive behavior from this vantage point. The defensive behavior system is viewed as having three modes that are activated by different levels of fear. Low levels of fear promote pre-encounter defenses, such as meal-pattern reorganization. Moderate levels of fear activate post-encounter defenses. For the rat, freezing is the dominant post-encounter defensive response. Since this mode of defense is activated by learned fear, forebrain structures such as the amygdala play a critical role in its organization. Projections from the amygdala to the ventral periaqueductal gray activate freezing. Extremely high levels of fear, such as those provoked by physical contact, elicit the vigorous active defenses that compose the circa-strike mode. Midbrain structures such as the dorsolateral periaqueductal gray and the superior colliculus play a crucial role in organizing this mode of defense. Inhibitory interactions between the structures mediating circa-strike and post-encounter defense allow for the rapid switching between defensive modes as the threatening situation varies.
\end{abstract}

The functional behavior systems paradigm provides a structural framework that can aid analysis of the environmental control, response topography, and neural mechanisms that determine behavior. One major characteristic of the behavior systems approach is that it views an animal as having a set of several genetically determined, prepackaged behaviors that it uses to solve a particular functional problem (e.g., feeding). If the current conditions demand that this problem must be solved immediately, the animal's behavioral repertoire may become restricted to that set of prepackaged behaviors. Bolles (1970) outlined a strikingly clear example of this in his species-specific defense reaction (SSDR) theory. SSDRs are the rat's innately determined defensive behaviors; freezing, fighting, and flight are examples. When the rat is confronted by a natural environmental threat (e.g., a predator) or an artificial one (e.g., an electric shock), its behavioral repertoire becomes restricted to its SSDRs. In such situations the rat finds it difficult, if not impossible, to execute a response that does not resemble an SSDR. However, the animal does have some flexibility, in that it has several SSDRs from which to choose. The assumption of an adaptationist approach, such as the behavioral systems

This paper is dedicated to the memory of Robert C. Bolles. The research was supported by National Institute of Mental Health Grant MH39786. The article was partly prepared while the author was a fellow at the Center for Advanced Study in the Behavioral Sciences supported by the John D. and Catherine T. MacArthur Foundation Grant 8900078. Thanks are due S. L. Young and J. P. DeCola for helpful comments. M.S.F. is affiliated with the Department of Psychology and the Brain Research Institute at the University of California, Los Angeles. Address reprint requests to M. S. Fanselow, Department of Psychology, University of California, Los Angeles, CA 90024-1563. paradigm, holds that the behavior selected from this limited repertoire will be the most effective one for the situation confronting the animal. When in a threatening situation, the rat will engage in the SSDR available that offers the highest probability of survival in those circumstances. A critical task for the investigator analyzing a behavior system is therefore to determine how the animal matches behavior to its environment. The rules of response selection that govern this choice must be specified. These rules should allow switching between behaviors when environmental conditions change. This paper outlines a particular response-selection rule for SSDR selection. It then goes on to describe the neural organization of SSDRs, and concludes by describing how this organization allows for effective switching between SSDRs.

\section{MODES OF DEFENSIVE RESPONDING AND RESPONSE SELECTION}

In Bolles's (1970) original formulation of SSDR theory, he suggested that SSDRs have a hierarchical organization and that the hierarchy was rearranged if a dominant SSDR frequently met with failure. Punishment, resulting from such failures, was the mechanism that caused restructuring of the hierarchy. This view met with both empirical and logical opposition (Bolles, 1975; Fanselow, Sigmundi, \& Williams, 1987). SSDRs do not respond to operant punishment contingencies in a way that suggests response weakening (Bolles, 1975; Bolles \& Riley, 1973; Fanselow \& Lester, 1988). Additionally, learning via punishment is unlikely to allow the rapid change between SSDRs that would provide for effective defense in real-life situations (Fanselow et al., 1987). 
An alternate view proposes that neutral features of the environment dictate the behavior observed (e.g., Blanchard, Fukunaga, \& Blanchard, 1976; Bolles \& Collier, 1976; Bolles \& Fanselow, 1980). A frightened rat might try to escape if an escape exit is present, fight if a target for fighting exists, and freeze if neither of these environmental stimuli is available. Essentially, this idea is Tolman's (1932) notion of behavioral support stimuli. A rat motivated by a given level of fear will express that fear in a behavioral topography dictated by supporting stimuli in the environment. While this view may be intuitively reasonable and widely held, it has met with severe empirical contradiction. Most of the situations taken as evidence for this behavioral support stimulus hypothesis have not only altered the neutral, supporting stimuli in the environment, they have confounded the level of fear or aversive stimulation. For example, experiments that show defensive fighting, as opposed to freezing, not only place another rat in the situation but also use shock intensities and densities that are much greater than those optimal for freezing.

An experimental finding called the immediate-shock deficit provides an illustrative example. Initially taken as evidence favoring the behavioral support stimulus hypothesis, it shows how subtle manipulations thought to affect only support stimuli actually affect the level of fear. Rats given a few minutes to explore a cage before the delivery of footshock show the SSDR of freezing following shock. This freezing occurs because contextual cues become associated with shock (Blanchard \& Blanchard, 1969; Fanselow, 1980). The immediate-shock deficit occurs when rats are given the same shock without this preshock exploratory period. Under these conditions, the rats do not freeze. Blanchard et al. (1976) interpreted this finding in terms of the behavioral support

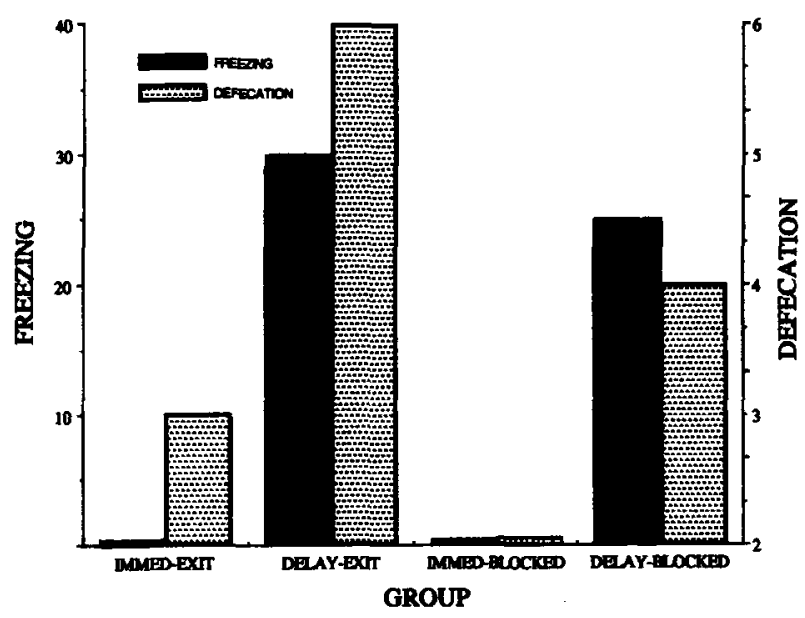

Figure 1. Rats were observed for freezing (left axis, shaded bars) or defecation (right axis, dashed bars) following shock given either immediately (IMMED-) or 2-min (DELAY-) after placement in an observation chamber. This shock treatment was factorially combined with either an open (-EXIT) or a closed (-BLOCKED) exit hole in the chamber. Based on Fanselow (1986). stimulus hypothesis. That is, according to their explanation, during the preshock exploratory period, the delayed-shock rats learned that the cage contained no escape exits and therefore froze; the immediate-shock rats, in the absence of a preshock exploratory period, did not have the opportunity to learn about the lack of escape exits, and therefore engaged in a more dominant flight response rather than freezing.

In subsequent analyses, I found this interpretation to be incorrect (Fanselow, 1986, 1990; Fanselow, DeCola, \& Young, 1993). The difference between the immediateand delayed-shock rats is in their respective levels of fear, not in how their fear translates into performance. Giving shock immediately upon placement in the chamber simply does not condition any fear to the chamber. The fact that the immediate-shock deficit appears not only in freezing, but in two other fear-induced behaviors, defecation and fear-induced analgesia (Fanselow, 1986; Fanselow, Landeira-Fernandez, DeCola, \& Kim, 1994), indicates that it is a deficit in fear conditioning. Neither defecation nor fear-induced analgesia would be expected to vary with the presence or absence of escape exits, as they should accompany any fear-induced behavior, including flight. Further evidence in support of this argument is provided by the finding that the immediate-shock deficit persists over three exposures to immediate shocks (Fanselow, DeCola, DeOca, \& LandeiraFernandez, in press); since a 3-min observation period followed each immediate shock, the rats had ample time to learn that the chamber had no escape exits, yet despite this, they never displayed freezing after any of the immediate shocks. Moreover, the presence of escape exits, and even experience with these exits, does not alter behavior in either immediate- or delayed-shock rats (Fanselow, 1986). The deficit is affected by manipulations that might be expected to influence context-shock associations. It is attenuated, for instance, by increasing the salience of the context by adding a potent stimulus such as a loud tone (Fanselow, 1990) or by shock preexposure (Fanselow et al., 1993). Figure 1 shows the results of one of these experiments, in which rats, on placement in a chamber containing either an $8-\mathrm{cm}^{2}$ escape exit or a solid wall, received either an immediate or a delayed ( 2 min after placement) shock. The graph shows that during a 5-min postshock observation period, the presence or absence of an escape exit did not affect either freezing or defecation. Both indices of fear were high in the delayed-shock rats, while there were no signs of fear in the rats that had received immediate shock.

Fanselow and Lester (1988) conducted a series of experiments designed to test more conclusively the behavioral support stimulus hypothesis. To ensure that the level of fear was constant, rats experienced light-shock pairings off baseline and then had the light probed into various environments that differed with respect to the type of support stimuli they provided. Light was chosen as a conditional stimulus (CS) because other researchers suggested that a light CS supported less freezing than a tone CS (e.g., Ayres, Axelrod, Mercker, Muchnik, \& 
Table 1

\begin{tabular}{|c|c|c|c|}
\hline Defensive Mode & Activating Stimuli & $\begin{array}{l}\text { Critical Anatomical } \\
\text { Structures }\end{array}$ & $\begin{array}{c}\text { Consequent } \\
\text { Behaviors }\end{array}$ \\
\hline Pre-encounter & $\begin{array}{l}\text { entering area having some } \\
\text { predatory potential }\end{array}$ & unknown & $\begin{array}{l}\text { meal pattern } \\
\text { reorganization, } \\
\text { protective nest } \\
\text { maintenance, } \\
\text { stretched approach }\end{array}$ \\
\hline Post-encounter & $\begin{array}{l}\text { detecting a predator in } \\
\text { present environment }\end{array}$ & $\begin{array}{l}\text { amygdala, ventral } \\
\text { periaqueductal gray }\end{array}$ & $\begin{array}{l}\text { freezing, opiate } \\
\text { analgesia, } \\
\text { potentiated startle }\end{array}$ \\
\hline Circa-strike & $\begin{array}{l}\text { contact with predator is } \\
\text { occurring or inevitable }\end{array}$ & $\begin{array}{l}\text { dorsolateral periaqueductal } \\
\text { gray, superior colliculus }\end{array}$ & $\begin{array}{l}\text { defensive fighting, } \\
\text { escape, threat displays, } \\
\text { jump attack, } \\
\text { nonopiate analgesia }\end{array}$ \\
\hline
\end{tabular}

Vigorito, 1985; Sigmundi \& Bolles, 1983). Freezing was the dominant response to the CS, regardless of environmental support; the conditioned light never enhanced a response other than freezing. On the basis of their observation that the level of fear seemed to be a more important determinant of behavior than the type of environmental support present, Fanselow and Lester proposed a response-selection rule, whereby it was the prey's perception of likelihood of consumption by a predator (referred to as predatory imminence) that decided its defensive-behavioral topography. Imminence was influenced by such factors as the spatial distance of threat and the temporal likelihood of contact with the threat. Defensive behavior was divided into three stages (or, in Timberlake's terminology [e.g., Timberlake, 1993; Timberlake \& Lucas, 1989], modes) - namely, pre-encounter, post-encounter, and circa-strike (see Table 1). If the rat has to leave a safe nesting area for a more dangerous foraging area, it may do so in a manner that represents a compromise between risk factors and energy requirements. Such compromises in normal activities represent pre-encounter defensive behavior. Meal patterns will become increasingly reorganized as the probability of encountering a threat increases (Fanselow, Lester, \& Helmstetter, 1988; Helmstetter \& Fanselow, 1993). When the level of fear increases, perhaps because of actual detection of a predator, post-encounter defensive behavior replaces pre-encounter defense. For the rat, freezing is the dominant post-encounter defense, probably because it reduces the chance of detection and removes the releasing signals for attack if detected. This mode of defense is therefore abandoned only when physical contact with the threat is inevitable, at which point the rat engages in more active defenses, such as biting, jumping, and audible vocalizations, comprising circa-strike defensive behavior.

This predatory imminence continuum is easiest to describe in terms of physical distance between predator and prey (e.g., Blanchard, Blanchard, \& Hori, 1989). However, the continuum and the individual modes of responding can be profitably analyzed in the laboratory with easily controlled threats such as electric shocks. Elsewhere (Fanselow, 1989), I have pointed out that manipulating shock density allows one to model the entire continuum. Behaviors within each mode increase as shock density increases, up to a point at which the mode of defense changes and the next set of behaviors emerges (Fanselow, 1989; Helmstetter \& Fanselow, 1993). However, one can see changes between modes with even a single contact with a threat. The highest imminence modes of defense occur adjacent to contact and are gradually replaced by lower imminence behaviors as the time since contact increases. This pattern occurs with a brief exposure to either a cat (Blanchard et al., 1989) or an electric shock (Fanselow, 1982). Immediately after shock, the rat shows an activity burst (the circa-strike defensive mode) that gradually gives way to freezing (the post-encounter defensive mode). The next portion of this paper uses freezing as an index of post-encounter defense and the activity burst as an index of circa-strike defense to analyze the neural apparatus mediating these two modes of defense. The final section provides theory and data showing how these two neural systems interact in ways that allow effective switching between these modes of defense.

\section{NEURAL CIRCUITRY MEDIATING POST-ENCOUNTER DEFENSES}

Figure 2 presents a heuristic model for the neural mediation of post-encounter defense. It has long been noted that the ventrolateral aspects of the midbrain periaqueductal gray matter (vPAG) are important for fear-related behaviors (Liebman, Mayer, \& Liebeskind, 1970; Lyon, 1964). Electrolytic lesions of this region decrease freezing and reduce the suppression of food-related behaviors that normally occurs in aversive situations (Kim, Rison, \& Fanselow, 1993; Liebman et al., 1970; Lyon, 1964). Neurons intrinsic to the caudal portions of the VPAG are critical to freezing, as chemical destruction limited to cell bodies in this region also attenuates freezing (Kiernan \& Cranney, 1992; LeDoux, Iwata, Cicchetti, \& Reis, 1988). This area proves critical to the opioid analgesia that accompanies fear (Helmstetter \& Landeira-Fernandez, 1991). Opioids in vPAG mediate fear-induced analgesia via projections that inhibit ascending pain information within the dorsal horn of the spinal cord (Watkins, Co- 


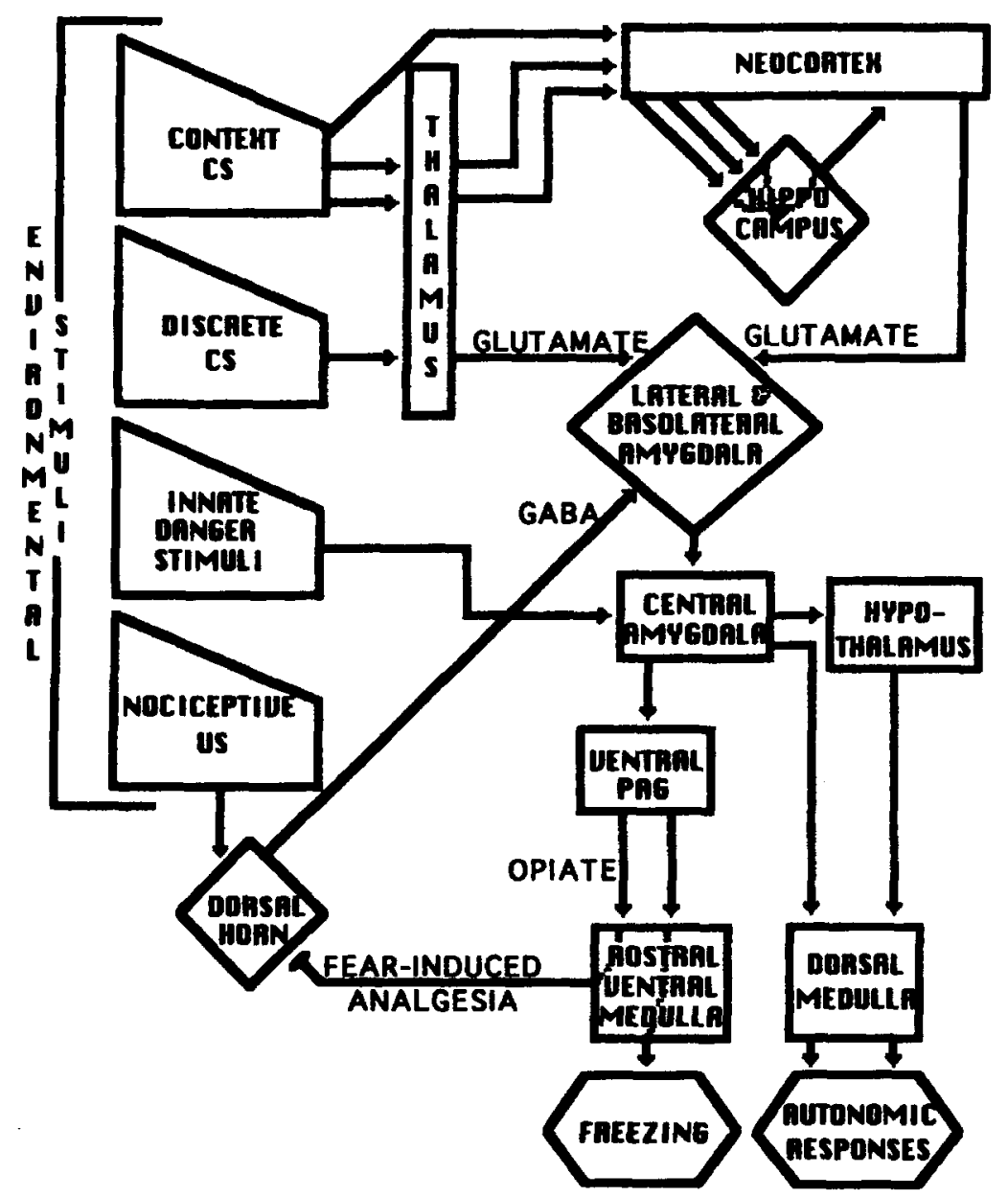

Figure 2. A model of the neural circuitry underlying the post-encounter defensive mode, including a model for the neural circuitry mediating conditional fear. Except for also showing the analgesia that inhibits nociceptive input at the dorsal horn of the spinal cord, the diagram is simplified to present only excitatory connections between structures. Stimulus inputs are clustered to the left, and behavioral responses are clustered at the bottom. The relevant neural structures are labeled inside geometric forms. Some potential neurotransmitters are labeled adjacent to the relevant connections. Additional detail on some portions of the circuit can be found in Fanselow and Kim (1992).

belli, \& Mayer, 1982). However, the vPAG circuits mediating freezing do not utilize opioids, as opioid antagonists do not affect performance of the freezing response (Helmstetter \& Fanselow, 1987).

When freezing occurs in situations motivated by electric shock, the response is purely a conditional response to shock-associated cues (e.g., Fanselow, 1980). Thus, the vPAG must get information about the presence of stimuli associated with shock from forebrain areas involved in the encoding and storage of such associations. For associations between shock and neutral stimuli, the amygdala seems to be crucial (see Davis, 1992; LeDoux, 1992, for reviews). The lateral and basolateral areas of this structure appear to be involved in forming the association between environmental cues and shock, while the central nucleus provides an output pathway for the generation of responses (Fanselow \& Kim, 1994; Helmstetter, 1992). The amygdala projects to the vPAG (e.g., Hopkins \& Holstege, 1978; Shipley, Ennis, Rizvi, \& Behbehani, 1991), and in this way can generate freezing and analgesia to shock-associated stimuli (Helmstetter, 1992). However, the autonomic changes that are concomitant with freezing involve not the PAG (LeDoux et al., 1988) but, rather, connections between the amygdala and the dorsal medullary nuclei that control autonomic function (Kapp, Whalen, Supple, \& Pascoe, 1992). As shown in Figure 2, this involves direct projections as well as indirect connections via the hypothalamus (Kapp et al., 1992; LeDoux, et al., 1988). Not shown in Figure 2 are two other components of post-encounter defense that are initiated by the central nucleus of the amygdala but do not depend on the PAG. One is the potentiated startle response pro- 


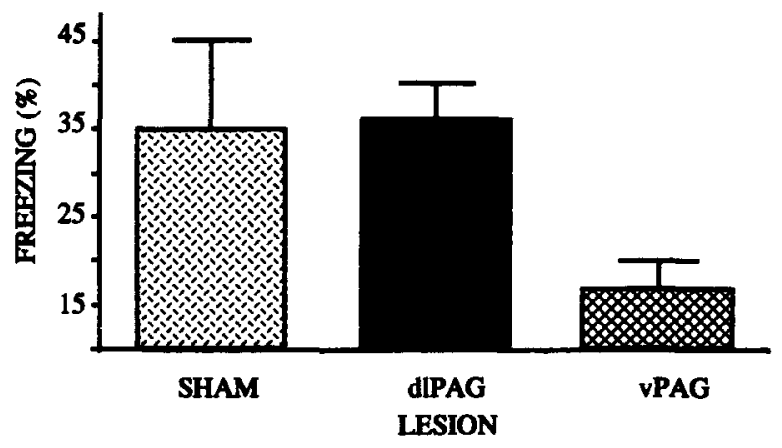

Figure 3. The freezing of rats to the presence of a cat. Plexiglas walls prevented the cat from contacting the rat. Rats had electrolytic lesions of the dIPAG or the vPAG, or were sham controls. Based on De Oca, DeCola, Liebeskind, and Fanselow (1994).

duced by shock-associated stimuli (Davis, 1992; Kiernan \& Cranney, 1992; Yeomans \& Pollard, 1993), while the other is a general enhancement of arousal and attention that may facilitate further information processing (Kapp et al., 1992).

Figure 2 shows that discrete CSs such as tone and light have direct access to association-formation regions in the amygdala via thalamic sensory relays (Clugnet \& LeDoux, 1990; LeDoux, Sakaguchi, \& Reis, 1984). In many experiments conducted in my laboratory (see, e.g., Figure 1), the CS is not a discrete cue such as a brief tone or light, but rather the contextual cues present at the time of shock. While the amygdala is necessary for fear of such contextual CSs (e.g., Helmstetter, 1992; Kim et al., 1993; Phillips \& LeDoux, 1992), direct projections from thalamus to amygdala are insufficient for contextual fear conditioning; thus, acquisition of fear to contextual stimuli also requires the hippocampus, as well as, perhaps, the neocortex (Kim \& Fanselow, 1992; Phillips \& LeDoux, 1992; Young, Bohenek, \& Fanselow, 1994).

Most of the evidence linking these neural structures to defensive behavior came from studies using electric shock as the threatening stimulus. However, there are studies implicating the same neural structures when freezing in the rat stems from an ethologically relevant stimulus-namely, a cat. The same amygdala lesions that block freezing to shock-associated cues also block freezing in response to cats (Blanchard \& Blanchard, 1972). Figure 3 displays recent data indicating that freezing in rats provoked by a cat was reduced by lesions of the vPAG (De Oca, DeCola, Liebeskind, \& Fanselow, in press). This corresponds well with the similar effect obtained with shock-related freezing, as lesions of the PAG that excluded the ventrolateral portions of the structure did not cause this attenuation.

The above circuitry provides a picture of the organization of post-encounter defense. The most obvious characteristic when visually observing a rat in this defensive mode is that it freezes. However, several other behavioral changes occur that, while less obvious, still play an important role. Autonomic and analgesic re- sponses most likely support the freezing response, in order for it to be accomplished more effectively. For example, analgesia prevents painful stimuli from provoking recuperative behaviors that would interfere with freezing (Bolles \& Fanselow, 1980; Fanselow, 1984; Fanselow \& Baackes, 1982). Analgesia also helps to regulate conditioning so that the level of freezing is appropriate to the situation (Young \& Fanselow, 1992). The amygdala plays a central role in the organization of the post-encounter mode of defense. It gathers and integrates information from various sources and, given the appropriate combination of input, instigates the various behavioral actions (freezing, analgesia, autonomic changes, and enhanced arousal and startle) that constitute the post-encounter mode (cf. Timberlake, 1993).

\section{DORSOLATERAL PAG AND CIRCA-STRIKE DEFENSIVE BEHAVIOR}

A structure that is conspicuously absent from Figure 2 is the portion of the PAG dorsal to the vPAG whose defensive functions are outlined above. Research primarily from Bandler, Depaulis and their colleagues (Bandler, Carrive, \& Zhang, 1991; Bandler \& Depaulis, 1988; Carrive, Bandler, \& Dampney, 1989; Depaulis, Bandler, \& Vergnes, 1989; Depaulis, Keay, \& Bandler, 1992) suggests that this area may be involved in defensive responding. Chemical stimulation applied directly to the lateral PAG elicits autonomic and behavioral responses that appear defense-like. Unfortunately, these researchers have not examined whether these areas subserve defense when it is elicited by environmental stimuli, as opposed to directly stimulating brain structures. The results shown in Figure 3 indicate that lesions of the areas Bandler and his colleagues have found to be responsive to chemical stimulation, but that spare the vPAG, do not affect defensive freezing elicited by a cat. These results are consistent with the literature, reviewed above, examining freezing to shock-associated stimuli; even large lesions of the PAG do not reduce freezing if the ventrolateral portions of the structure are spared.

A resolution to this discrepancy can be found in the behavior systems approach. Freezing is part of the postencounter mode of responding. Observations of animals with lateral PAG stimulation suggest that the behaviors bear more resemblance to the active circa-strike behaviors. Rats given chemical stimulation of the lateral PAG will display defensive upright postures and locomotion to conspecifics (Depaulis et al., 1989). Cats given similar stimulation exhibit "strenuous hindlimb movement" (Carrive et al., 1989). In my own observations of rats stimulated through electrodes implanted in the lateral PAG, running and turning behaviors reminiscent of the shock-elicited activity burst were apparent (Fanselow, 1991; cf. Fanselow, 1982). These observations motivated a study contrasting lesions of the vPAG with more dorsal lesions (Fanselow, 1991). Dorsal lesions damaged lateral, dorsolateral, and dorsomedial portions of the PAG, but did not cause any damage below the aqueduct. I 


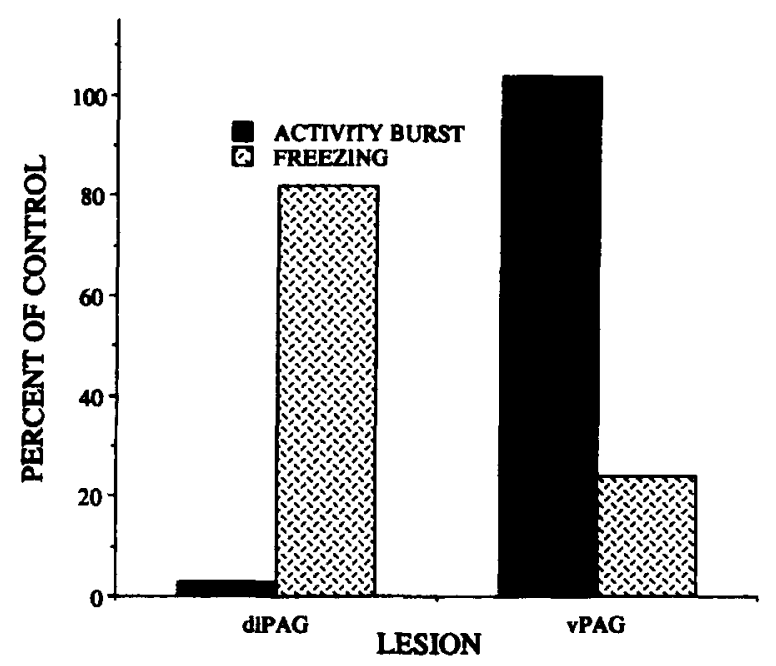

Figure 4. The data for rats with either dIPAG or vPAG lesions as a percentage of the activity burst (shaded bars) or freezing (patterned bars) of sham-operated controls. Based on Fanselow (1989).

therefore refer to these lesions as dorsolateral PAG (dlPAG) lesions. The activity burst and freezing were used as indices of circa-strike and post-encounter defenses, respectively. The results were clear (see Figure 4): Lesions of dIPAG virtually eliminated the activity burst to shock, but did not affect freezing. Exactly the opposite effect occurred with vPAG lesions, which had no effect on the activity burst, but strongly attenuated freezing. Thus, the behavior systems approach provides a good resolution to the conflict between the lesion and stimulation data. The dIPAG and $\mathrm{VPAG}$ are involved in different modes of defense, the former with the circastrike mode, and the latter with the post-encounter mode.

Figure 5 shows potential neural circuitry mediating circa-strike defenses. Nociceptive input activates dIPAG, as would occur with the electric footshock used in the previous experiment described. There are direct projections from the spinal cord and the trigeminal nucleus to the PAG that are likely to carry nociceptive information (e.g., Blomqvist \& Craig, 1991). This should not be taken to mean that no other sensory stimuli can elicit circa-strike defense. The superior colliculus, which, particularly in its deep layers, receives input from all sensory modalities except olfaction, projects to the immediately adjacent dIPAG, and is implicated in defensive behavior (Redgrave \& Dean, 1991). Stimulation of the superior colliculus can produce defensive responses (Dean, Redgrave, \& Westby, 1989). The form of defensive reactions evoked by chemical stimulation of the dIPAG is influenced by environmental stimuli. Rats, for example, will show an oriented defensive response to tactile stimuli that are presented contralaterally, but not to those that are presented ipsilaterally, to unilateral chemical stimulation of the PAG (see Bandler \& Depaulis, 1991, for a review).

Circa-strike behavior can be broken down into several modules, such as jump attack, escape, and upright posture, each consisting of several actions (cf. Timberlake \& Lucas, 1989). These distinct modules appear to have anatomical counterparts longitudinally organized within the PAG (Bandler et al., 1991; Depaulis et al.,

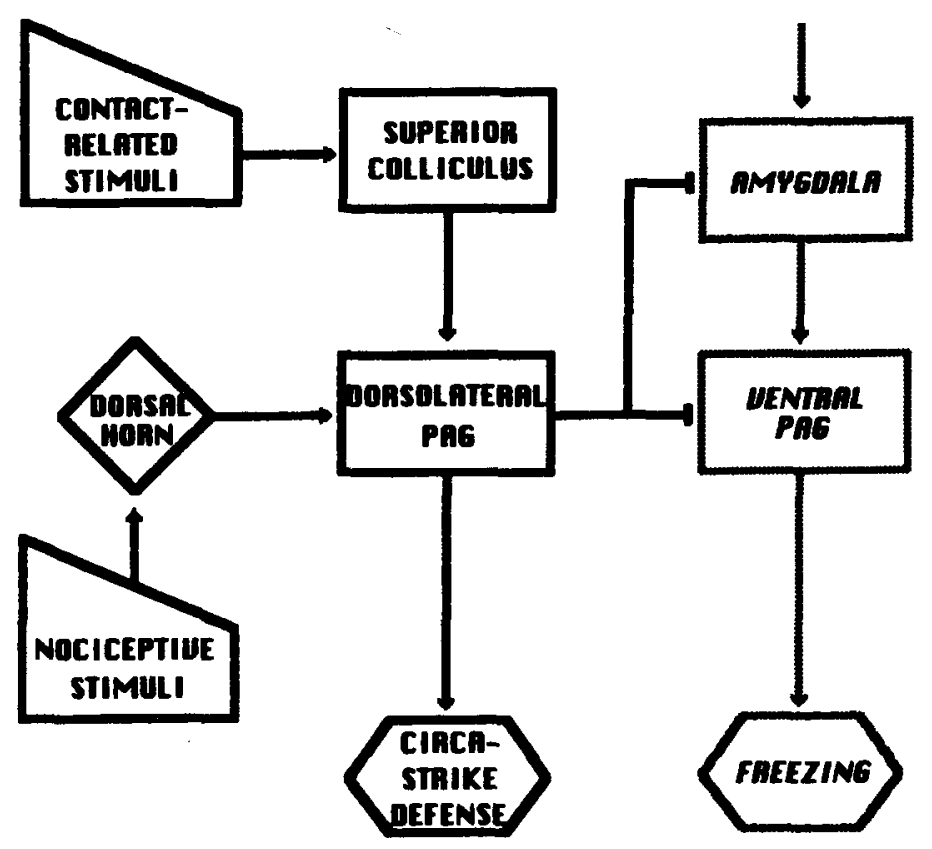

Figure 5. A simplified circuit diagram of the circa-strike mode of defense in black. The model also indicates inhibitory connections to the post-encounter mode (rightmost circuit). 
1992). Stimulation of neurons in the caudal third of the rat's PAG produces rapid forward locomotion intermixed with forward hops and jumps. More rostrally placed cells, in the intermediate third of the PAG, produce the defensive upright posture and backing away. Neurons in the same locations drive the characteristic autonomic components of each module (Bandler et al., 1991; Depaulis et al., 1992). Additionally, vocalization (sonic and/or ultrasonic) is a characteristic action within circa-strike modules. The PAG clearly plays a role in the control of vocalizations (Jurgens, 1991; Larson, 1991). Chemical stimulation of dlPAG sites that elicit forward avoidance (running, hopping, jumping) also elicit ultrasonic vocalizations in the $22-28 \mathrm{kHz}$ range (Depaulis et al., 1992). This frequency range is characteristic of the rat's alarm cries (Blanchard, Blanchard, Agullana, \& Weis, 1991). Finally, stimulation of the dlPAG produces analgesia that may prevent recuperative behaviors from interfering with circa-strike behavior. Unlike the analgesia produced as part of the post-encounter module, this analgesia is nonopioid (Cannon, Prieto, Lee, \& Liebeskind, 1982). Interestingly, nonopioid analgesia occurs unconditionally for a brief period of time immediately following electric shock (Grau, 1984; Maier, 1989)-exactly the time that the activity burst occurs.

\section{DIFFERENCES IN THE ORGANIZATION OF POST-ENCOUNTER AND CIRCA-STRIKE DEFENSE}

When one examines a behavior system in such detail, the resulting circuit diagram may not be as neat and symmetrical as the hierarchical diagram resulting from a purely conceptual analysis. In this section, I wish to highlight some of these asymmetries in order to clarify the relationship between the description of defense provided here and the more general description of behavior systems. Such a clarification serves to address several empirical and theoretical issues surrounding fear and defensive behavior.

Timberlake (1993; Timberlake \& Lucas, 1989) organizes the behavior systems paradigm in a hierarchy going from superordinate systems through subsystems, modes, and modules, to subordinate actions. The system described here is that of defense against environmental threat, while the subsystem is that of antipredator defense, which, as noted earlier, is broken down into three modes-pre-encounter, post-encounter, and circa-strike. The latter two are emphasized in my neural analysis. For post-encounter defense in the rat, there appears to be one module - that of freezing (functional reasons for such a limited module are outlined in detail by Fanselow \& Lester, 1988). This blurs the distinction between mode and module for post-encounter defense. However, the circa-strike mode consists of several distinct modules, including locomotion away from the predator and a jump attack toward the predator. As indicated in Figure 5, the superior colliculus may provide the sensory input needed to drive these individual modules (Redgrave \& Dean, 1991).

According to Timberlake (1993), each module incorporates several actions. In the current organization, these actions at the very least are physically compatible, so that they can occur simultaneously; often, they are supportive or even facilitatory. A rat in post-encounter mode can simultaneously freeze and adjust muscle tone in a manner that would potentiate startle (Leaton \& Borszcz, 1985). Arousal, tachycardia, hypertension, and analgesia may each facilitate one or both of these actions. All the actions of the post-encounter mode are initiated by the amygdala. In contrast, the actions that comprise the circa-strike mode are triggered by the dIPAG rather than the amygdala. Thus, it is stimulation of the dIPAG that results in the various actions constituting that mode of defense, including supportive actions such as nonopioid analgesia and a redirection of blood flow from viscera and skin to skeletal muscle (e.g., Lovick, 1991). It is important to consider this point when performing physiological manipulations that affect fear and defensive behavior, since manipulations that affect all aspects of a particular mode must occur upstream from the point at which the individual components diverge. For postencounter defense, manipulations downstream from the amygdala will only influence some actions of the postencounter mode (e.g., LeDoux et al., 1988). Stimulation of the VPAG provokes immobility, but not autonomic changes characteristic of defense (Lovick, 1991).

Another asymmetry between post-encounter and circa-strike defense concerns the sensory input that drives these two modes. The post-encounter mode of defense is activated by complex stimuli, such as an intrinsically innocuous cue that has acquired its threatening value via a learned association (Estes \& Skinner, 1941), or the features of a predatory animal that distinguish it from a nonpredator (Hirsch \& Bolles, 1980). Thus, the sensory input that drives the post-encounter mode strongly depends on the forebrain information processing structures briefly sketched in the top portion of Figure 2 . On the other hand, circa-strike behaviors need to be sudden reactions to potentially disastrous contact. They are driven by more direct sensory input, without complex forebrain processing. Note that nociceptive stimulation provides an important input to both modes of responding, but that it plays different roles for each mode. In post-encounter defense, it does not provoke a response itself but rather promotes learning as a Pavlovian reinforcer (Fanselow, 1980). In the circa-strike mode, on the other hand, nociception plays the role of a direct elicitor of behavior. The neural pathways for these two differing functions of nociceptive input must be distinct because dlPAG lesions eliminated the response-eliciting component of an electric shock without impairing its ability to promote association formation (see Figure 4). Thus, we see a clear dissociation of the two effects of a Pavlovian unconditional stimulus; its ability to support conditioning (i.e., reinforcement) is independent of its ability to elicit behavior. As a result, conditional responses may 
differ dramatically from unconditional responses (Fanselow, 1989).

\section{INTERACTIONS BETWEEN THE POST- ENCOUNTER AND CIRCA-STRIKE MODES}

The survival of animals that prey on the rat indicates that, despite its complexity, the rat's defensive behavior system does not always succeed. The complexity of innately wired circa-strike behaviors also indicates that rats can grasp survival from out of the clutches of a predator, at least often enough to pass on the genes required for circa-strike behavior. These two remarks suggest that oscillation between post-encounter and circa-strike modes must take place. Critically, if post-encounter defense fails, survival may depend on an instantaneous transition to circa-strike defense. There is some evidence for these rapid transitions. The freezing of a rat in a shock-associated environment is immediately eliminated by an electric shock (Fanselow, 1982), and the opioid analgesia momentarily succumbs to a nonopioid one (Maier, 1989).

Such a transition would be best accomplished by an active inhibition of the post-encounter mode when the environment activates the circa-strike mode. Figure 5 outlines inhibitory connections from dIPAG to vPAG and amygdala to accomplish this transition, and there are monosynaptic projections from dlPAG to amygdala that may also accomplish the inhibition (Rizvi, Ennis, Behbehani, \& Shipley, 1991). Additionally, recent evidence indicates that electrical stimulation of the dlPAG causes a long-lasting inhibition of vPAG that is consistent with a pathway such as the one suggested here (Chandler, Liu, Murphy, Shipley, \& Behbehani, 1993). Note that connections are necessary not just to the vPAG, but also to the amygdala if all the actions of the post-encounter mode are to be terminated. For example, if inhibition were entirely within the PAG, the autonomic components of post-encounter defense could interfere with the autonomic components of circa-strike defense.

The presence of such inhibitory connections leads to an interesting prediction that was recently tested in my laboratory (Fanselow et al., in press). If these inhibitory connections are eliminated, the loss of inhibition may lead to enhanced post-encounter defense (freezing). We reckoned that such an effect would be most likely to occur in situations in which particularly intense shockdelivery parameters led to less-than-expected levels of freezing. The shock might be driving the dlPAG and its inhibitory links and in that way attenuating the freezing. One such situation develops with shock delivery scheduled at very short intershock intervals. Little freezing transpires during the shock session (Bolles \& Riley, 1973 ) or in a shock-free test given $24 \mathrm{~h}$ later (Fanselow \& Tighe, 1988; Fanselow et al., 1993). We chose to look at the situation in which freezing was examined $24 \mathrm{~h}$ after the last shock, as it precludes an account in terms of response competition caused by the elicitation of circa-strike behaviors (i.e., the activity burst). We con- firmed that rats given three shocks spaced $3 \mathrm{sec}$ apart froze about half as much as rats given similar shocks spaced $60 \mathrm{sec}$ apart. Lesions of dlPAG raised freezing in the short-intershock-interval group to the level of the long-intershock-interval rats, but did not affect freezing in the long group. On the other hand, freezing was severely attenuated in rats with vPAG lesions. Since freezing was tested on a shock-free day, the results indicate that the dIPAG lesions actually enhanced conditional responding. This suggests that the dlPAG's inhibitory influence may have been on the amygdala circuits responsible for conditioning. Again, an inhibition at this level makes sense because the amygdala provides the only location in which the entirety of the post-encounter mode can be inhibited. In an earlier paper (Fanselow et al., 1993), we suggested that a similar shock-induced inhibition of conditioning might be partly responsible for the observation that rats do not freeze if they receive an electric shock immediately after placement in an observation chamber. As described earlier and shown in Figure 1, to successfully condition, a short delay must pass between placement and shock. We exposed rats to one of these immediate shocks per day for three days and then, during a shock-free test, examined them for freezing. No freezing occurred in sham-, vPAG-, or superior-colliculuslesioned animals. However, significant levels of freezing were conditioned in rats that received the same immediate shocks following lesions of the dlPAG. The alleviation of these deficits in learned fear strongly implies an active inhibition of post-encounter neural structures by the circa-strike mode.

\section{FINAL REMARKS}

In this paper, I have analyzed fear by using a top-down approach guided by the behavior systems view. Both functional and behavioral considerations have led to a relatively complete picture of the mechanisms mediating the class of behaviors Bolles (1970) labeled speciesspecific defensive reactions. A multileveled analysis guided by knowledge of the organization of behavior and its evolutionary purpose helps answer questions about the molecular underpinnings of behavior. In turn, tools provided by the neural analyses help answer questions about behavior and function. It seems that an understanding of such phenomena at multiple levels, working hand in hand with each other, will facilitate discovery and lead to a more comprehensive understanding of behavior and biology.

\section{REFERENCES}

Ayres, J. J. B., Axelrod, H., Mercker, E., Muchnik, F., \& ViGORITO, M. (1985). Concurrent observations of barpress suppression and freezing: Effects of CS modality and on-line vs. off-line training. Animal Learning \& Behavior, 13, 44-50.

Bandler, R., Carrive, P., \& Zhang, S. P. (1991). Integration of somatic and autonomic reactions within the midbrain periaqueductal grey: Viscerotopic, somatotopic and functional organization. In G. Holstege (Ed.), Progress in brain research: Vol. 87. Role of the 
forebrain in sensation and behavior (pp. 269-305). Amsterdam: Elsevier.

Bandler, R., \& Depaulis, A. (1988). Elicitation of intraspecific defence reactions in the rat from midbrain periaqueductal grey by microinjection of kainic acid without neurotoxic effects. Neuroscience Letters, 88, 291-296.

BANDLER, R., \& Depaulis, A. (1991). Midbrain periaqueductal gray control of defensive behavior in the cat and the rat. In A. Depaulis \& R. Bandler (Eds.), The midbrain periaqueductal grey matter: Functional, anatomical and immunohistochemical organization (NATO ASI Series A: Vol. 213, pp. 175-198). New York: Plenum.

Blanchard, D. C., \& Blanchard, R. J. (1969). Crouching as an index of fear. Journal of Comparative \& Physiological Psychology, 67, 370-375.

Blanchard, D. C., \& Blanchard, R. J. (1972). Innate and conditioned reactions to threat in rats with amygdaloid lesions. Journal of Comparative \& Physiological Psychology, 81, 281-290.

Blanchard, R. J., Blanchard, D. C., Agullana, R., \& Weis, S. M. (1991). Twenty-two $\mathrm{kHz}$ alarm cries to presentation of a predator, by laboratory rats living in visible burrow systems. Physiology \& Behavior, 50, 967-972.

Blanchard, R. J., Blanchard, D. C., \& HoRI, K. (1989). An ethoexperimental approach to the study of defense. In R. J. Blanchard, P. F Brain, D. C. Blanchard, \& S. Parmigiani (Eds.), Ethoexperimental approaches to the study of behavior (NATO ASI Series D: Vol. 48, pp. 114-136). Boston: Kluver Academic Publishers.

Blanchard, R. J., Fukunaga, K. K., \& Blanchard, D. C. (1976). Environmental control of defensive reactions to footshock. Bulletin of the Psychonomic Society, 8, 129-130.

Blompvist, A., \& Craig, A. D. (1991). Organization of spinal and trigeminal input to the PAG. In A. Depaulis \& R. Bandler (Eds.), The midbrain periaqueductal grey matter: Functional, anatomical and immunohistochemical organization (NATO ASI Series A: Vol. 213, pp. 345-363). New York: Plenum.

BoLLES, R. C. (1970). Species-specific defense reactions and avoidance learning. Psychological Review, 77, 32-48.

Bolles, R. C. (1975). Theory of motivation (2nd ed). New York: Harper \& Row.

Bolles, R. C., \& Collier, A. C. (1976). Effect of predictive cues on freezing in rats. Animal Learning \& Behavior, 4, 6-8.

Bolles, R. C., \& Fanselow, M. S. (1980). A perceptual-defensiverecuperative model of fear and pain. Behavioral \& Brain Sciences, 3, 291-301.

Bolles, R. C., \& Riley, A. L. (1973). Freezing as an avoidance response: Another look at the operant-respondent distinction. Learning \& Motivation, 4, 268-275.

Cannon, J. T., Prieto, G. J., Lee, A., \& Liebeskind, J. C. (1982). Evidence for opioid and non-opioid forms of stimulation-produced analgesia in the rat. Brain Research, 243, 315-321.

Carrive, P., Bandler, R., \& Dampney, R. A. L. (1989). Somatic and autonomic integration in the midbrain of the unanesthetized decerebrate cat: A distinctive pattern evoked by excitation of neurones in the subtentorial portion of the midbrain periaqueductal grey. Brain Research, 483, 251-258.

Chandler, S. C., Liu, H., Murphy, A. Z., Shipley, M. T., \& BehbeHANI, M. M. (1993). Columnar organization in PAG: Physiological evidence for intercolumnar interactions. Society for Neuroscience Abstracts, 19, 1408.

Clugnet, M.-C., \& LeDoux, J. E. (1990). Synaptic plasticity in fear conditioning circuits: Induction of LTP in the lateral nucleus of the amygdala by stimulation of the medial geniculate body. Journal of Neuroscience, 10, 2818-2824.

DAvIS, M. (1992). The role of the amygdala in conditioned fear. In J. P. Aggleton (Ed.), The amygdala: Neurobiological aspects of emotion, memory, and mental dysfunction (pp. 255-305). New York: Wiley-Liss.

Dean, P., Redgrave, P., \& Westby, G. W. M. (1989). Event or emergency? Two response systems in the mammalian superior colliculus. Trends in Neuroscience, 12, 137-147.

De Oca, B., DeCola, J. P., Liebeskind, J. C., \& Fanselow, M. S. (in press). Differential effects of ventral and dorsal periaqueductal gray (PAG) lesions on defensive responses of rats to cats, shock and taste aversion. Society for Neuroscience Abstracts.

Depaulis, A., Bandler, R., \& Vergnes, M. (1989). Characterization of pretentorial periaqueductal gray neurons mediating intraspecific defensive behaviors in the rat by microinjections of kainic acid. Brain Research, 486, 121-132.

Depaulis, A., Keay, K. A., \& Bandler, R. (1992). Longitudinal neuronal organization of defensive reactions in the midbrain periaqueductal gray region of the rat. Experimental Brain Research, 90, 307318.

Estes, W. K., \& Skinner, B. F. (1941). Some quantitative properties of anxiety. Journal of Experimental Psychology, 29, 390-400.

FANSELOW, M. S. (1980). Conditional and unconditional components of post-shock freezing. Pavlovian Journal of Biological Sciences, $15,177-182$.

FANSELOW, M. S. (1982). The post-shock activity burst. Animal Learning \& Behavior, 10, 448-454.

FANSELOW, M. S. (1984). Opiate modulation of both the active and inactive components of the postshock reaction: Parallels between naloxone pretreatment and shock intensity. Behavioral Neuroscience, 98, 269-277.

FANSELOW, M. S. (1986). Associative vs. topographical accounts of the immediate shock freezing deficit in rats: Implications for the response selection rules governing species specific defensive reactions. Learning \& Motivation, 17, 16-39.

FANSELOW, M. S. (1989). The adaptive function of conditioned defensive behavior: An ecological approach to Pavlovian stimulus substitution theory. In R. J. Blanchard, P. F. Brain, D. C. Blanchard, \& S. Parmigiani (Eds.), Ethoexperimental approaches to the study of behavior (NATO ASI Series D: Vol. 48, pp. 151-166). Boston: Kluver Academic Publishers.

FANSELOW, M. S. (1990). Factors governing one trial contextual conditioning. Animal Learning \& Behavior, 18, 264-270.

FANSELOW, M. S. (1991). The midbrain periaqueductal gray as a coordinator of action in response to fear and anxiety. In A. Depaulis \& R. Bandler (Eds.), The midbrain periaqueductal grey matter: Functional, anatomical and immunohistochemical organization (NATO ASI Series A: Vol. 213, pp. 151-173). New York: Plenum.

FANSELOW, M. S., \& BAACKES, M. P. (1982). Conditioned fear-induced opiate analgesia on the formalin test: Evidence for two aversive motivational systems. Learning \& Motivation, 13, 220-221.

Fanselow, M. S., DeCola, J. P., De Oca, B., \& Landeira-Fernandez, J. (in press). Ventral and dorsolateral regions of the midbrain periaqueductal gray control different stages of defensive behavior: Dorsolateral PAG lesions enhance the defensive freezing produced by massed and immediate shock. Aggressive Behavior.

Fanselow, M. S., DeCola, J. P., \& Young, S. L. (1993). Mechanisms responsible for reduced contextual conditioning with massed unsignaled unconditional stimuli. Journal of Experimental Psychology: Animal Behavior Processes, 19, 121-137.

FANSELOW, M. S., \& KIM, J. J. (1992). The benzodiazepine inverse agonist $\mathrm{DMCM}$ as an unconditional stimulus for fear-induced analgesia: Implications for the role of $\mathrm{GABA}_{\mathrm{A}}$ receptors in fear related behavior. Behavioral Neuroscience, 106, 336-344.

Fanselow, M. S., \& KIM, J. J. (1994). Acquisition of contextual Pavlovian fear conditioning is blocked by application of an NMDA receptor antagonist $D, L-2$-amino-5-phosphonovaleric acid to the basolateral amygdala. Behavioral Neuroscience, 108, 210-212.

Fanselow, M. S., Landeira-Fernandez, J., DeCola, J. P., \& Kim, J. J. (1994). The immediate shock deficit and postshock analgesia: Implications for the relationship between the analgesic CR and UR. Animal Learning \& Behavior, 22, 72-76.

FANSELOW, M. S., \& LESTER, L. S. (1988). A functional behavioristic approach to aversively motivated behavior: Predatory imminence as a determinant of the topography of defensive behavior. In R. C. Bolles \& M. D. Beecher (Eds.), Evolution and learning (pp. 185211). Hillsdale, NJ: Erlbaum.

Fanselow, M. S., Lester, L. S., \& Helmstetter, F. J. (1988). Changes in feeding and foraging patterns as an antipredator defensive strategy: A laboratory simulation using aversive stimulation in 
a closed economy. Journal of the Experimental Analysis of Behavior, 50, 361-374.

Fanselow, M. S., Sigmundi, R. A., \& Williams, J. (1987). Response selection and the hierarchical organization of species specific de fense reactions: The relationship between freezing, flight and defensive burying. Psychological Record, 37, 381-386.

Fanselow, M. S., \& Tighe, T. J. (1988). Contextual conditioning with massed versus distributed unconditional stimuli. Journal of Experimental Psychology: Animal Behavior Processes, 14, 187-199.

GRAU, J. W. (1984). Influence of naloxone on shock-induced freezing and analgesia. Behavioral Neuroscience, 98, 278-292.

Helmstetter, F. J. (1992). The amygdala is essential for the expression of conditional hypoalgesia. Behavioral Neuroscience, 106, 518-528.

Helmstetter, F. J., \& Fanselow, M. S. (1987). Effects of naltrexone on learning and performance of conditional fear-induced freezing and opioid analgesia. Physiology \& Behavior, 39, 501-505.

Helmstetter, F. J., \& Fanselow, M. S. (1993). Aversively motivated changes in meal patterns of rats in a closed economy: The effects of shock density. Animal Learning \& Behavior, 21, 168-175.

Helmstetter, F. J., \& Landeira-Fernandez, J. (1991). Conditional hypoalgesia is attenuated by naltrexone applied to the periaqueductal gray. Brain Research, 537, 88-92.

HiRsCH, S. M., \& BolLES, R. C. (1980). On the ability of prey to recognize predators. Zeitschrift für Tierpsychologie, 54, 71-84.

Hopkins, D. A., \& Holstege, G. (1978). Amygdaloid projections to the mesencephalon, pons and medulla oblongata in the cat. Experimental Brain Research, 32, 529-547.

JURGENS, U. (1991). Neurochemical study of PAG control of vocal behavior. In A. Depaulis \& R. Bandler (Eds.), The midbrain periaqueductal grey matter: Functional, anatomical and immunohistochemical organization (NATO ASI Series A: Vol. 213, pp. 11-21). New York: Plenum.

Kapp, B. S., Whalen, P. J., Supple, W. F., \& Pascoe, J. P. (1992) Amygdaloid contributions to conditioned arousal and sensory information processing. In J. P. Aggleton (Ed.), The amygdala: Neurobiological aspects of emotion, memory, and mental dysfunction (pp. 229-254). New York: Wiley-Liss

Kiernan, M., \& Cranney, J. (1992). Excitotoxic lesions of the central nucleus of the amygdala but not of the periaqueductal gray block integrated fear responding as indexed by both freezing responses and augmentation of startle. Society for Neuroscience $A b$ stracts, 18, 1566.

KIM, J. J., \& FANSELOW, M. S. (1992). Modality specific retrograde amnesia of fear following hippocampal lesions. Science, 256, 675677

Kim, J. J., Rison, R. A., \& Fanselow, M. S. (1993). Effects of amygdala, hippocampus, and periaqueductal gray lesions on short- and long-term contextual fear. Behavioral Neuroscience, 107, 10931098 .

LARSON, C. R. (1991). Activity of PAG neurons during conditioned vocalization in the macaque monkey. In A. Depaulis \& $\mathrm{R}$. Bandler (Eds.), The midbrain periaqueductal grey matter: Functional, anatomical and immunohistochemical organization (NATO ASI Series A: Vol. 213, pp. 23-40). New York: Plenum.

Leaton, R. N., \& Borszcz, G. S. (1985). Potentiated startle: Its relation to freezing and shock intensity in rats. Journal of Experimental Psychology, 11, 421-428

LeDoux, J. E. (1992). Emotion and the amygdala. In J. P. Aggleton (Ed.), The amygdala: Neurobiological aspects of emotion, memory and mental dysfunction (pp. 339-351). New York: Wiley-Liss.

LeDoux, J. E., Iwata, J., Cicchetti, P., \& Reis, D. J. (1988). Different projections of the central amygdaloid nucleus mediate autonomic and behavioral correlates of conditioned fear. Journal of Neuroscience, 8, 2517-2529.

LeDoux, J. E., Sakaguchi, A., \& Reis, D. J. (1984). Subcortical efferent projections of the medial geniculate nucleus mediate emo- tional responses conditioned to acoustic stimuli. Journal of Neuroscience, 4, 683-698.

Liebman, J. M., Mayer, D. J., \& Liebeskind, J. C. (1970). Mesencephalic central gray lesions and fear-motivated behavior in rats. Brain Research, 23, 353-370.

LovicK, T. A. (1991). Interactions between descending pathways from the dorsal and ventrolateral periaqueductal gray matter in the rat. In A. Depaulis \& R. Bandler (Eds.), The midbrain periaqueductal grey matter: Functional, anatomical and immunohistochemical organization (NATO ASI Series A: Vol. 213, pp. 101-120). New York: Plenum.

LYON, M. (1964). The role of central midbrain structures in conditioned responding to aversive noise in the rat. Journal of Comparative Neurology, 122, 407-429.

MAIER, S. F. (1989). Determinants of the nature of environmentallyinduced hypoalgesia. Behavioral Neuroscience, 103, 131-143.

Phillips, R. G., \& LEDoux, J. E. (1992). Differential contribution of amygdala and hippocampus to cued and contextual fear conditioning. Behavioral Neuroscience, 106, 274-285.

Redgrave, P., \& Dean, P. (1991). Does the PAG learn about emergencies from the superior colliculus? In A. Depaulis \& R. Bandler (Eds.), The midbrain periaqueductal grey matter: Functional anatomical and immunohistochemical organization (NATO ASI Series A: Vol. 213, pp. 199-209). New York: Plenum.

Rizvi, T. A., EnNis, M., Behrehani, M., \& Shipley, M. T. (1991). Connections between the central nucleus of the amygdala and the midbrain periaqueductal gray: Topography and reciprocity. Journal of Comparative Neurology, 303, 121-131.

Shipley, M. T., EnNis, M., Rizvi, T. A., \& Behbehani, M. M. (1991). Topographical specificity of forebrain inputs to the midbrain periaqueductal gray: Evidence for discrete longitudinally organized input columns. In A. Depaulis \& R. Bandler (Eds.), The midbrain periaqueductal grey matter: Functional, anatomical and immunohistochemical organization (NATO ASI Series A: Vol. 213, pp. 417448). New York: Plenum.

Sigmundi, R. A., \& Bolles, R. C. (1983). CS modality, context conditioning, and conditioned freezing. Animal Learning \& Behavior $11,205-212$

TimberLaKe, W. (1993). Behavior systems and reinforcement: An integrative approach. Journal of the Experimental Analysis of Behavior, 60, 105-128.

Timberlake, W., \& LuCAS, G. A. (1989). Behavior systems and learning: From misbehavior to general principles. In S. B. Klein \& R. R. Mowrer (Eds.), Contemporary learning theories: Instrumental conditioning theory and the impact of biological constraints on learning (pp. 237-275). Hillsdale, NJ: Erlbaum.

Tolman, E. C. (1932). Purposive behavior in animals and men. New York: Appleton.

Watkins, L. R., CoBElli, D. A., \& MAYER, D. J. (1982). Classical conditioning of front paw and hind paw footshock induced analgesia (FSIA): Naloxone reversibility and descending pathways. Brain Research, 243, 119-132.

Yeomans, J. S., \& Pollard, B. A. (1993). Amygdala efferents mediating electrically evoked startle-like responses and fear potentiation of acoustic startle. Behavioral Neuroscience, 107, 596-610.

YounG, S. L., BoHENEK, D. L., \& FANSELOW, M. S. (1994). NMDA processes mediate anterograde amnesia of contextual fear conditioning induced by hippocampal damage: Immunization against amnesia by contextual preexposure. Behavioral Neuroscience, 108, 19-29.

YounG, S. L., \& FANSELOW, M. S. (1992). Associative regulation of Pavlovian fear conditioning: US intensity, incentive shifts \& latent inhibition. Journal of Experimental Psychology: Animal Behavior Processes, 18, 400-413

(Manuscript received November 19, 1993; revision accepted for publication June 13, 1994.) 